\title{
Comparison of the Effects of Native Vitamin D and Eldecalcitol on Muscular Strength and Dynamic Balance in Patients with Postmenopausal Osteoporosis
}

\author{
Naohisa Miyakoshi, MD, PhD Norimitsu Masutani, MD, PhD Yuji Kasukawa, MD, PhD \\ Daisuke Kudo, MD, PhD Kimio Saito, MD, PhD Toshiki Matsunaga, MD, PhD \\ and Yoichi Shimada, MD, PhD
}

\begin{abstract}
Objectives: Previous studies have suggested that the effects of vitamin D in preventing osteoporotic fractures result in part from its influence on fall prevention. However, the effects of vitamin $\mathrm{D}$ on dynamic balance as a contributor to fall prevention have not been fully evaluated. Moreover, few studies have compared the effects of native and active forms of vitamin D. The objective of this preliminary randomized prospective study was to compare the effects of native vitamin D and eldecalcitol on muscular strength and dynamic balance in postmenopausal patients undergoing denosumab treatment for osteoporosis. Methods: A total of 30 women with postmenopausal osteoporosis were randomly assigned to a native $\mathrm{D}$ group (administered denosumab and native vitamin D with calcium) or an ELD group (administered denosumab and eldecalcitol) and were followed up for 6 months. The following parameters were compared: the strengths of the back extensor and lower extremity muscles; static balance evaluated using the one-leg standing test; and dynamic balance evaluated using the 10 -m walk test, the functional reach test, the timed up and go test, and the total length of the trajectory of the center of gravity (LNG) measured using a dynamic sitting balance measurement device. Results: Compared to baseline measurements, back extensor and knee extensor strengths had significantly increased after 6 months of treatment in the native $\mathrm{D}$ group $(\mathrm{P}<0.05)$ but not in the ELD group. In contrast, LNG significantly improved in both groups after 6 months $(\mathrm{P}<0.05)$. No significant differences between the two groups were seen in any of these measured parameters after treatment. Conclusions: Both native vitamin D + denosumab and eldecalcitol + denosumab were effective for improving dynamic sitting balance in postmenopausal women with osteoporosis.
\end{abstract}

Key Words: balance; eldecalcitol; muscle strength; osteoporosis; vitamin D

\section{INTRODUCTION}

Most osteoporotic fractures in the elderly are caused by falls. Because impairment of balance and muscle weakness are the major risk factors for falls in the elderly, ${ }^{1)}$ the assessment of muscle strength and balance are central to evaluating the tendency to fall and to instigating preventive measures against falls. When assessing balance, we should consider dynamic balance as well as static balance. Clinically, rep- resentative methods of measuring static balance include the one-leg standing test (OLS) and the standing center-of-gravity examination, ${ }^{2)}$ whereas dynamic balance in the elderly is commonly evaluated using the timed up and go test (TUG) ${ }^{3)}$ and the functional reach test (FRT). $\left.{ }^{4}\right)$

In regard to falls, the assessment of dynamic balance is considered to be more important than that of static balance. Many falls are caused by sudden external stimuli such as slipping or tripping ${ }^{5)}$; falls arising as a consequence of bal-

Received: July 20, 2020, Accepted: October 14, 2020, Published online: October 30, 2020

Department of Orthopedic Surgery, Akita University Graduate School of Medicine, Akita, Japan

Correspondence: Naohisa Miyakoshi, MD, PhD, Department of Orthopedic Surgery, Akita University Graduate School of Medicine,

1-1-1 Hondo, Akita 010-8543, Japan, E-mail: miyakosh@doc.med.akita-u.ac.jp

Copyright (C) 2020 The Japanese Association of Rehabilitation Medicine

(1) (-) $\odot$ This is an open-access article distributed under the terms of the Creative Commons Attribution Non-Commercial No Derivatives (CC BY-NC-ND) 4.0 License. http://creativecommons.org/licenses/by-nc-nd/4.0/ 
ance dysfunction are more closely related to the ability to respond to external stimuli and dynamic balance than to maintaining a static posture. $\left.{ }^{6}\right)$ We therefore developed a device for measuring dynamic balance in the sitting position. The device is capable of measuring trunk balance ability by adding a disturbance that periodically tilts the seat surface in the frontal plane; we have previously reported its utility in balance evaluation. ${ }^{7-9)}$ Dynamic balance evaluation with the subject in the sitting position is safer than other positions for assessing balance in elderly individuals at risk of falls.

Studies have shown that vitamin D, an essential hormone for bone health, exerts positive effects on balance and muscle strength and is effective in preventing falls, especially in the elderly. ${ }^{10-13)}$ However, much of the clinical research into the effects of vitamin D regarding fall prevention has been done using native vitamin $\mathrm{D}$ with calcium supplementation, ${ }^{10-13)}$ whereas research into active vitamin $\mathrm{D}_{3}$, including eldecalcitol [2 $\beta$-(3-hydroxypropyloxy)-1,25-dihydroxyvitamin $\mathrm{D}_{3}$ ], remains insufficient.

Among many anti-osteoporotic agents, denosumab, a human monoclonal antibody against receptor activator of nuclear factor $\kappa-\mathrm{B}$ ligand, is used worldwide as one of the most effective agents. Denosumab selectively inhibits osteoclastogenesis and exerts potent inhibitory effects on bone turnover, thereby increasing bone mineral density (BMD) and preventing osteoporotic fractures. ${ }^{14-17)}$ In Japan, to prevent hypocalcemia resulting from denosumab treatment, use of the insurance-covered chewable tablet of native vitamin D with calcium supplementation is recommended. However, in clinical practice, active vitamin $\mathrm{D}_{3}$, including eldecalcitol, is also used with denosumab. Consequently, the purpose of this open-label, prospective, randomized study was to compare the effects of native vitamin $\mathrm{D}$ with calcium supplementation and eldecalcitol on balance (both dynamic and static) and muscle strength in postmenopausal patients undergoing denosumab treatment for osteoporosis. This preliminary study examined the effects of native vitamin $\mathrm{D}$ and eldecalcitol in a limited number of subjects.

\section{METHODS}

\section{Patients and Study Design}

A total of 30 women ( $\geq 60$ years old) with postmenopausal osteoporosis, no history of treatment for osteoporosis, and in whom measuring physical function parameters was feasible, were recruited to this open-label, prospective, 6-month randomized study. Osteoporosis was diagnosed according to the criteria proposed by the Japanese Society for Bone and
Mineral Research (2012 revision). ${ }^{18)}$ Briefly, patients with: (1) fragility fracture in either the lumbar spine or proximal femur; (2) other fragility fracture and BMD $<80 \%$ of the young adult mean (YAM); or (3) BMD $\leq 70 \%$ or -2.5 standard deviations below the YAM were diagnosed as having osteoporosis.

Subjects with comorbidities such as gastrectomy; renal failure; or bone diseases such as cancer-induced bone loss, primary hyperparathyroidism, hyperthyroidism, Cushing's syndrome, multiple myeloma, Paget's disease of the bone, or osteogenesis imperfecta were excluded from this study. Subjects with the following conditions who could have neuromuscular or musculoskeletal diseases were also excluded because of the increased risk of falls: dementia, Parkinson's disease, cranial nerve disorders, spinal cord disorders, antipsychotic drug usage, or severe osteoarthritis of the knee.

Subjects were randomly allocated to either the native D group $(n=15)$ or the ELD group $(n=15)$. In the native $D$ group, patients were treated with denosumab (60 mg subcutaneously every 6 months) in combination with orally administered cholecalciferol at $400 \mathrm{IU} /$ day $(10 \mu \mathrm{g} /$ day $)$ and calcium at $610 \mathrm{mg} /$ day (Denotas; Daiichi Sankyo, Tokyo, Japan). In the ELD group, patients were treated with denosumab (60 mg subcutaneous injection every 6 months) in combination with orally administered eldecalcitol at $0.75 \mu \mathrm{g} /$ day (Edirol; Chugai Pharmaceutical Co., Tokyo, Japan). We used the RAND function in Excel to randomize the subjects. Enrolled subjects with a RAND value of less than 0.5 were assigned to the native D group, whereas those with a RAND value of more than 0.5 were allocated to the ELD group. In the ELD group, to minimize the risk of hypercalcemia (in accordance with the warning given in the drug package insert for eldecalcitol), calcium supplementation was not administered; however, active intake of dietary calcium was not prohibited.

During the 6-month treatment period, nine patients dropped out of the study. The reasons were cessation of hospital visits for any reason (1 patient in the native D group, 3 patients in the ELD group), numbness in the extremities (1 patient in the native D group, 3 patients in the ELD group), or withdrawn consent (1 subject in the ELD group). Consequently, data from 21 subjects (13 patients in the native D group, 8 patients in the ELD group) were included in the final analyses (Fig. 1). The protocol for this randomized prospective study was approved by the ethics committee at our institute (approval no. 1188), and the study was conducted at Oga-Minato General Hospital. Written informed consent for the study and publication of its results was obtained from all patients. 


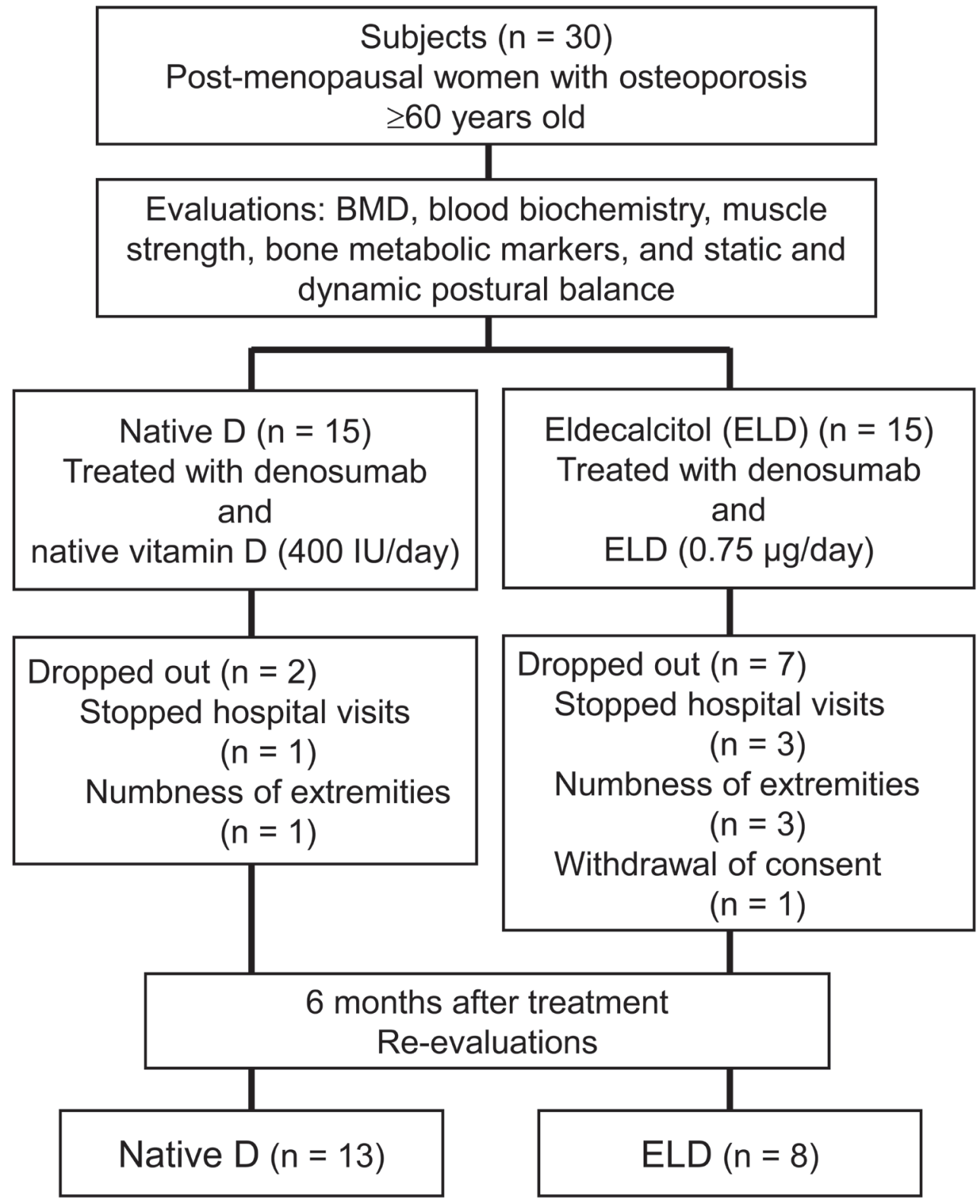

Fig. 1. Flowchart depicting the steps involved in the recruitment process. BMD, bone mineral density.

\section{Evaluations}

Age (years), height (m), body weight (kg), and body mass index $\left(\mathrm{BMI}, \mathrm{kg} / \mathrm{m}^{2}\right)$ were recorded for all subjects at the beginning of this study. The parameters described below were measured before treatment (i.e., at baseline) and after 6 months of treatment.

\section{Bone Mineral Density}

BMD was measured at the lumbar spine (antero-posterior measurement of the lumbar spine at the L2-4 level) and the proximal femur using dual-energy X-ray absorptiometry (QDR Discovery, Hologic, Bedford, MA, USA). The least significant change for this measurement modality has been reported as 1.69-2.08 at the lumbar spine and 1.49-1.77 at the femur. ${ }^{19}$ )

\section{Blood Biochemical Tests}

Serum samples were obtained from all subjects and the following biochemical analyses were performed. Total protein (TP, g/dL; reference range, 6.6-8.1 g/dL), serum albumin (Alb, g/dL; reference range, $4.1-5.1 \mathrm{~g} / \mathrm{dL}$ ), blood urea nitrogen (BUN, mg/dL; reference range, $8.0-20.0 \mathrm{mg} /$ $\mathrm{dL}$ ), creatinine (Cre, $\mathrm{mg} / \mathrm{dL}$; reference range, $0.65-1.07 \mathrm{mg} /$ $\mathrm{dL}$ ), estimated glomerular filtration rate (eGFR, $\mathrm{ml} / \mathrm{min} / 1.73$ 
$\mathrm{m}^{2}$; reference range, $\left.>60 \mathrm{ml} / \mathrm{min} / 1.73 \mathrm{~m}^{2}\right), 25$ hydroxyvitamin D [25(OH)D, $\mathrm{ng} / \mathrm{ml}$; reference range, $>20 \mathrm{ng} / \mathrm{ml}$, calcium (Ca, $\mathrm{mg} / \mathrm{dL}$; reference range, $8.8-10.1 \mathrm{mg} / \mathrm{dL}$ ), phosphorus (P, $\mathrm{mg} / \mathrm{dL}$; reference range, $2.7-4.6 \mathrm{mg} / \mathrm{dL}$ ), and tartrate-resistant acid phosphatase-5b (TRACP-5b, mU/ $\mathrm{dL}$; postmenopausal reference range, $120-420 \mathrm{mU} / \mathrm{dL}$ ) were measured using standard laboratory techniques before and after treatment. 25(OH)D and TRACP-5b were measured by chemiluminescent immunoassay (Liaison $25 \mathrm{OH}$ Vitamin D total; Hitachi Chemical Company, Tokyo, Japan) and enzyme immunoassay (Osteolinks TRACP-5b; SB Bioscience Co., Tokyo, Japan), respectively.

\section{Muscle Strength}

The mean values for both left and right grip strength were measured using a hand grip dynamometer (TH-YO2; Tsutsumi, Tokyo, Japan) with the subject in the upright position. Isometric back extensor strength was measured twice with the subject in the prone position using a dynamometer with a strain gauge (Digital Force Gauge DPU-1000N; Imada, Toyohashi, Japan); the larger of the two values was used. The coefficient of variation of these measurements was $2.3 \% .{ }^{20)}$ The iliopsoas (hip flexor) and quadriceps (knee extensor) muscle strengths were measured twice manually using a handheld dynamometer (Power Track II; JTEC Med, Salt Lake City, UT, USA); the mean values of the right and left sides were used for evaluation.

\section{Static Postural Balance}

Static standing balance was evaluated using the OLS. The OLS was performed with the patient standing on the left leg for as long as possible. The subject stood with eyes open and both arms aligned with the trunk without any support.

\section{Dynamic Postural Balance}

The 10-m walk test (10MWT) performed at a comfortable speed was used to assess dynamic physical function. ${ }^{21)}$ The FRT was used to assess dynamic balance control with a fixed base of support. ${ }^{22)}$ The participant was required to reach forward beyond the length of the extended arm without losing their balance. The participant stood with the legs positioned a shoulder-width apart and lifted one arm forward to $90^{\circ}$ with flexion of the shoulder and fingers extended. ${ }^{22}$ The test-retest reliability and validity of the FRT were reported in a previous study. ${ }^{22)}$ The TUG test was used as an indicator of dynamic balance control with a mobile base of support. The TUG test measures the time required for participants to rise from a standard armchair, walk $3 \mathrm{~m}$, turn, return, and sit down again. The reliability and validity of the TUG test has been reported previously. ${ }^{23)}$

\section{Dynamic Sitting Balance}

Dynamic sitting balance was evaluated using our originally developed dynamic balance measuring device. This device can calculate the center of pressure using three triaxial force sensors (USL06-H5; Tec Gihan, Kyoto, Japan) under external stimuli ${ }^{8}$ (Fig. 2). The intraclass correlation coefficient for intra-examiner reliability was 0.815 , and that for inter-examiner reliability was $0.789 .{ }^{24)}$ Subjects were instructed to sit on the platform as stably as possible with their gaze fixed on a horizontal mark placed $2 \mathrm{~m}$ away on the wall, to keep their lower limbs off the floor, and to cross their arms over their chest (Fig. 3). Subjects were challenged with an angular velocity of $0.40 \mathrm{~Hz}$ of sway toward the right or left sides with $3^{\circ}$ of inclination for $30 \mathrm{~s}$ to assess their ability to respond to external stimuli. The total length of the center of gravity $[\mathrm{LNG}(\mathrm{mm})]$ trajectory during the test was measured.

\section{Statistical Analysis}

We performed all analyses based on a modified intentionto-treat (ITT) population that included all randomized participants for whom valid data were available from baseline evaluations. As a second approach, a per-protocol (PP) analysis was performed that included only patients who continued treatment and underwent evaluations at 6 months after starting the experiment. Except for LNG, the MannWhitney U test was used for comparisons of baseline data between the two groups, whereas the Wilcoxon-signed rank test was used for within-group comparisons. Student's $t$-test was used for comparisons of baseline data or data after 6 months of treatment between the two groups and the paired $t$-test was used to make within-group comparisons for LNG. Furthermore, the percentage changes in $25(\mathrm{OH}) \mathrm{D}$, TRACP5 b, grip strength, back extensor strength, hip flexor strength, and knee extensor strength were calculated as [(value after treatment) - (value before treatment) $\times 100 /$ (value before treatment)] to evaluate the effects of native vitamin $\mathrm{D}$ or eldecalcitol on serum bone markers and muscle strength. The percentage changes in these parameters for the two groups were compared using the Mann-Whitney U test. The software used for the statistical analyses was IBM SPSS for Mac version 25.0 (IBM Corp., Armonk, NY, USA), and values of $\mathrm{P}<0.05$ were regarded as significant. 


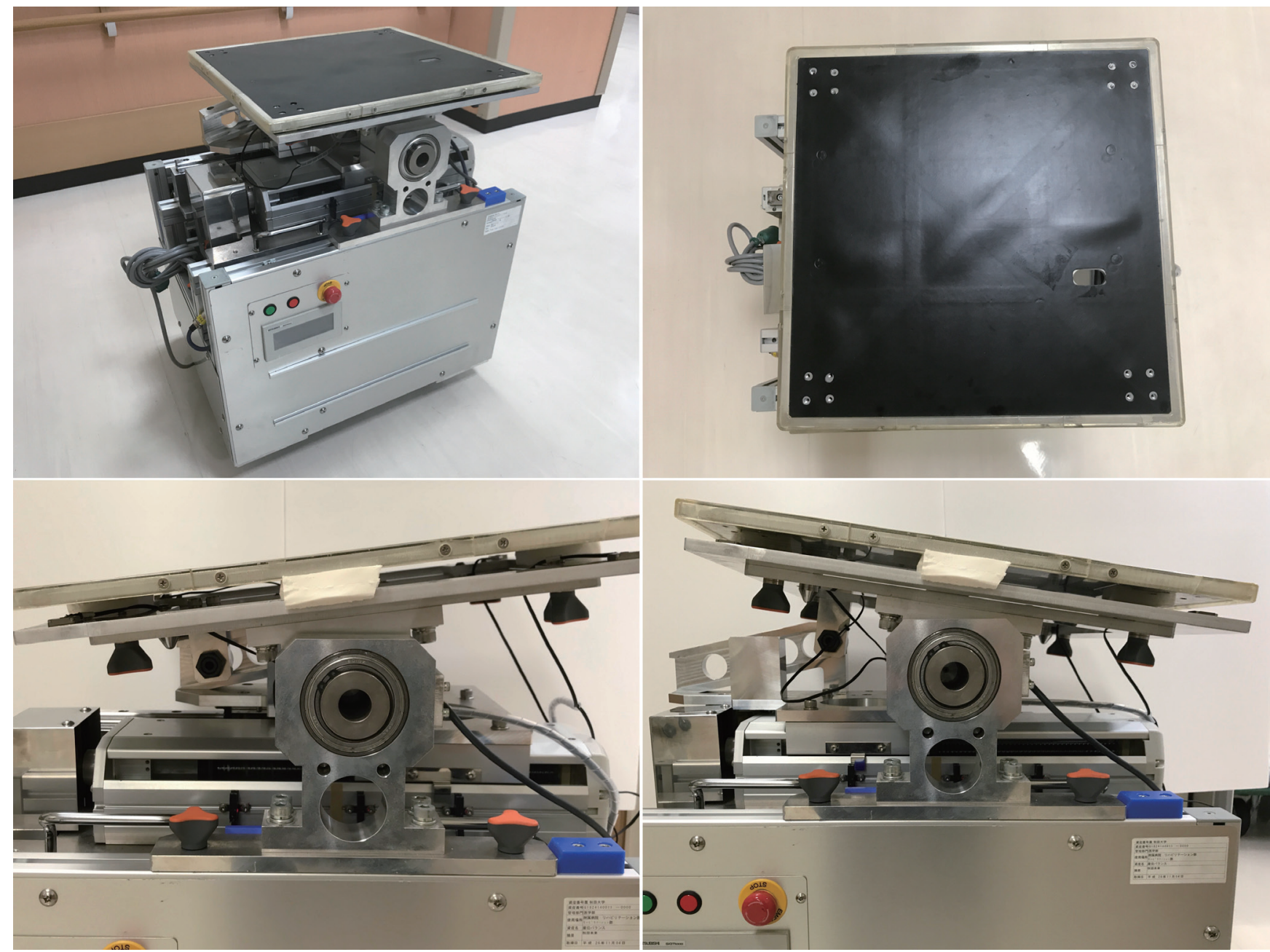

Fig. 2. Dynamic sitting balance was evaluated using an originally developed dynamic balance measuring device. The device can calculate the center of pressure using three triaxial force sensors under external stimuli. The seat surface can tilt to a maximum of $3^{\circ}$ to both the right and left sides.

\section{RESULTS}

\section{Baseline Data}

At baseline, apart from Alb in the modified ITT populations (Table 1) and TRACP-5b in the PP analysis (Table 2), all data evaluated in this study showed no significant differences between the two treatment groups. TRACP-5b levels were significantly higher in the native D group than in the ELD group at baseline, although the median levels of TRACP-5b in both groups were higher than the upper limit of the normal range.

\section{Effects of 6 Months of Treatment in Each Group}

As indications of bone metabolism, the serum 25(OH)D level and the lumbar spine BMD significantly increased in the native D group, and the serum TRACP-5b level significantly decreased after treatment (Table 2). These results are the expected consequences of denosumab treatment and native vitamin $\mathrm{D}$ administration. In terms of muscle strength and balance in the native D group, back extensor and knee extensor strengths increased significantly, and LNG decreased significantly after 6 months of treatment (Table 3). Other parameters did not show significant changes after treatment with denosumab and native vitamin $\mathrm{D}$.

In the ELD group, the serum TRACP-5b level decreased significantly after treatment (Table 2). This result also seemed to be a consequence of denosumab treatment. In terms of muscle strength and balance in the ELD group, only LNG was significantly affected and had decreased after treatment (Table 3). The other parameters did not show any significant change after treatment with eldecalcitol. 


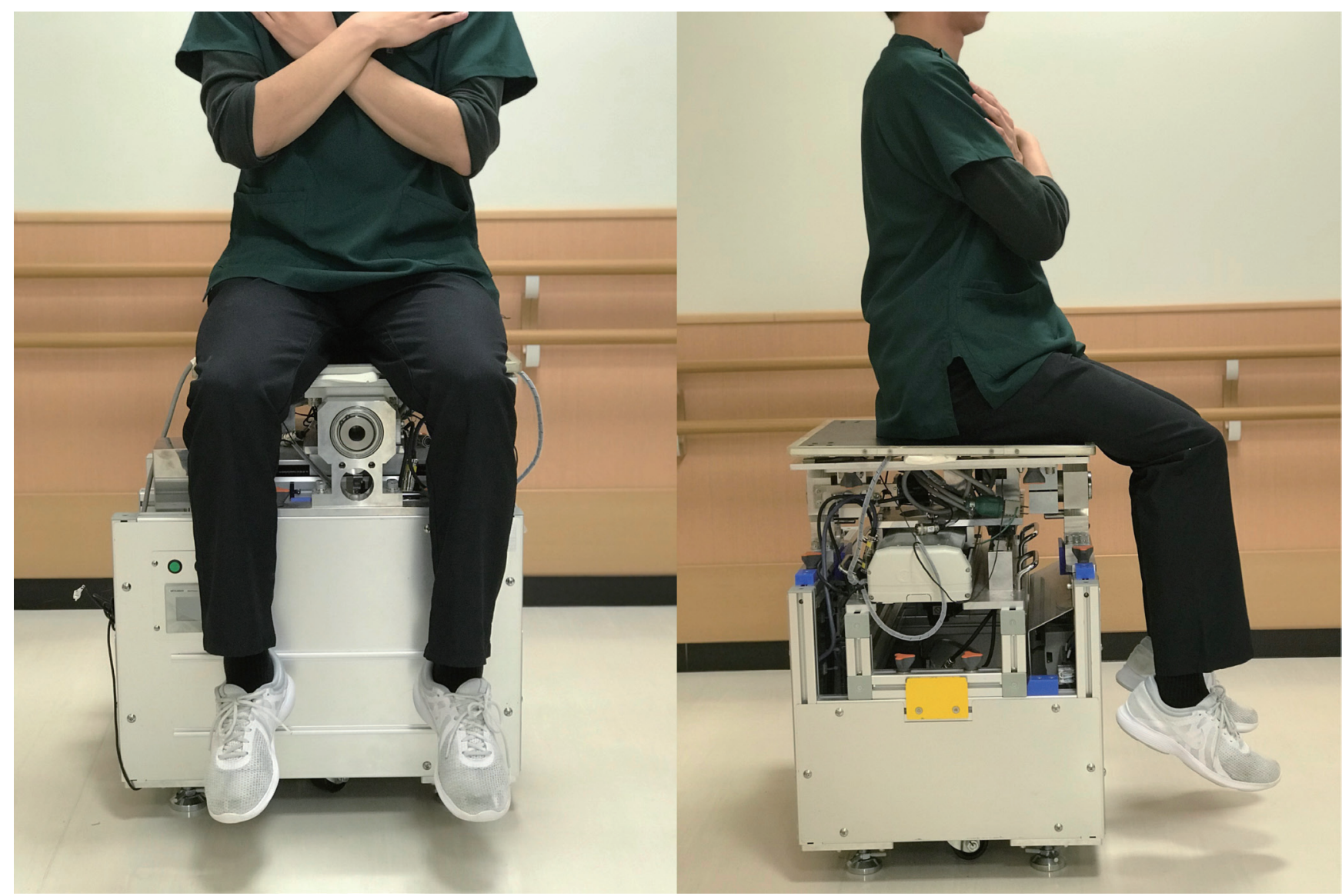

Fig. 3. Subjects sat on the device with arms folded across the anterior chest, eyes open, and with the feet not touching the floor. Subjects were then challenged for $30 \mathrm{~s}$ with an angular velocity of $0.40 \mathrm{~Hz}$ sway toward the right and left sides with $3^{\circ}$ of inclination.

\section{Comparison of Treatment Effects between the Two Groups}

After 6 months of treatment, as a consequence of native vitamin D supplementation in the native D group, serum $25(\mathrm{OH}) \mathrm{D}$ was significantly higher in the native $\mathrm{D}$ group than in the ELD group (Table 2). After treatment, serum phosphorus levels were significantly higher in the ELD group than in the native D group. No significant differences were seen between the groups in terms of muscle strength or the evaluated balance parameters. As a result of treatment, the percentage changes in the $25(\mathrm{OH}) \mathrm{D}$ and TRACP-5b levels in the native $\mathrm{D}$ group were significantly higher than those in the ELD group ( $\mathrm{P}=0.010$ and $\mathrm{P}=0.034$, respectively). However, there were no significant differences in the effects of treatment on muscle strength, including grip strength, back extensor strength, hip flexor strength, and knee extensor strength between the native D and the ELD groups (Table 4).

\section{DISCUSSION}

The negative impacts of vitamin D insufficiency or deficiency on human health involve not only diseases affecting bone metabolism, such as osteoporosis, but also other conditions. For example, lower levels of serum 25(OH)D are associated with many acute and chronic diseases, including autoimmune disorders, infectious diseases, cardiovascular diseases, type 2 diabetes mellitus, neurological disorders, and cancers. ${ }^{25)} \mathrm{A}$ recent meta-analysis showed that serum $25(\mathrm{OH}) \mathrm{D}$ concentrations $\leq 30 \mathrm{ng} / \mathrm{ml}$ were associated with significantly higher all-cause mortality than concentrations $\left.>30 \mathrm{ng} / \mathrm{ml}(\mathrm{P}<0.01){ }^{26}\right)$

Vitamin D is also important for muscle strength and balance, especially in the elderly. Vitamin D receptors (VDRs) have been identified in muscle tissue, ${ }^{27)}$ and the number of VDRs in muscle appears to decline with age. ${ }^{28)}$ Because muscle weakness is an important contributor to impaired bal- 
Table 1. Baseline characteristics of the participants in the modified intention-to-treat population

\begin{tabular}{|c|c|c|}
\hline & $\begin{array}{c}\text { Native D } \\
(\mathrm{n}=15)\end{array}$ & $\begin{array}{c}\text { ELD } \\
(\mathrm{n}=15)\end{array}$ \\
\hline Age (years) & $79.0(70.5,82.5)$ & $70.0(67.0,81.0)$ \\
\hline Height (m) & $1.47(1.44,1.54)$ & $1.48(1.46,1.54)$ \\
\hline Weight (kg) & $48.0(45.0,52.0)$ & $52.0(47.5,55.0)$ \\
\hline BMI $\left(\mathrm{kg} / \mathrm{m}^{2}\right)$ & $21.4(21.1,23.9)$ & $21.9(21.1,24.2)$ \\
\hline TP (g/dL) & $6.8(6.7,7.7)$ & $6.9(6.6,7.2)$ \\
\hline Alb (g/dL) & $4.2(4.0,4.4)^{\#}$ & $4.4(4.3,4.7)$ \\
\hline BUN (mg/dL) & $17.5(15.6,19.8)$ & $16.7(13.9,21.0)$ \\
\hline Cre (mg/dL) & $0.67(0.55,0.74)$ & $0.61(0.56,0.65)$ \\
\hline eGFR (ml/min/1.73 m²) & $61.9(56.8,63.9)$ & $74.6(66.7,77.3)$ \\
\hline 25(OH)D (ng/ml) & $27.5(25.0,35.8)$ & $24.0(16.8,36.5)$ \\
\hline $\mathrm{Ca}(\mathrm{mg} / \mathrm{dL})$ & $9.2(9.1,9.7)$ & $9.5(9.3,9.8)$ \\
\hline $\mathrm{P}(\mathrm{mg} / \mathrm{dL})$ & $3.2(3.1,3.5)$ & $3.7(3.3,3.9)$ \\
\hline TRACP-5b (mU/dL) & $558.0(484.0,638.0)$ & $481.0(448.0,505,0)$ \\
\hline \multicolumn{3}{|l|}{ BMD } \\
\hline Lumbar spine $\left(\mathrm{g} / \mathrm{cm}^{2}\right)$ & $0.678(0.650,0.762)$ & $0.710(0.658,0.794)$ \\
\hline YAM of lumbar spine (\%) & $67.0(64.0,75.5)$ & $70.0(64.0,85.0)$ \\
\hline Proximal femur $\left(\mathrm{g} / \mathrm{cm}^{2}\right)$ & $0.565(0.509,0.629)$ & $0.539(0.491,0.564)$ \\
\hline YAM of femur (\%) & $72.0(65.0,80.0)$ & $68.0(62.5,71.5)$ \\
\hline Grip strength (kg) & $19.6(16.4,21.8)$ & $23.5(17.8,25.1)$ \\
\hline Back extensor strength $(\mathrm{N})$ & $130.0(119.5,147.5)$ & $107.0(97.0,147.8)$ \\
\hline Hip flexor strength (N) & $155.1(138.6,165.9)$ & $128.4(107.5,163.5)$ \\
\hline Knee extensor strength $(\mathrm{N})$ & $164.8(155.0,179.4)$ & $158.4(145.0,166.4)$ \\
\hline One-leg standing test (s) & $22.0(4.1,59.3)$ & $13.0(6.4,26.1)$ \\
\hline 10-m walk test (s) & $6.7(5.6,9.6)$ & $8.5(7.5,9.4)$ \\
\hline FRT (cm) & $24.0(15.5,26.0)$ & $23.0(17.5,25.5)$ \\
\hline TUG (s) & $7.6(5.6,8.6)$ & $9.5(7.6,10.0)$ \\
\hline LNG $(\mathrm{mm})^{\mathrm{a}}$ & 2934 (334) & $3081(223)$ \\
\hline
\end{tabular}

Data are given as median (interquartile range), except for ${ }^{a}$ values presented as mean (standard deviation).

All parameters apart from LNG were compared using the Mann-Whitney U test. LNG was compared using Student's $t$-test. \# $\mathrm{P}=0.026$ vs ELD group by Mann-Whitney $\mathrm{U}$ test.

YAM, young adult mean; FRT, functional reach test; TUG, timed up and go test; LNG, total length of the center of gravity trajectory.

ance and functional limitations in the elderly, ${ }^{29)}$ the administration of vitamin $\mathrm{D}$ is considered an important measure to prevent falls in the elderly. In the clinical treatment of osteoporosis, additional effects against falls of using the active form of vitamin D are also postulated. This study compared the effects of native vitamin D with calcium supplementation and eldecalcitol on muscular strength and dynamic and static balance in patients with postmenopausal osteoporosis who were undergoing treatment with denosumab. Concomitant use of vitamin D during denosumab treatment is not only beneficial in preventing hypocalcemia but may also help prevent falls by exerting effects on muscles and balance.
However, the effects on muscles and balance of vitamin D in combination with denosumab treatment have never been studied. In particular, the differences between administration of native vitamin D and eldecalcitol with regard to the impact on dynamic balance require clarification. The present study focused on these points.

Eldecalcitol is an activated vitamin $\mathrm{D}_{3}$ analog ${ }^{30}$ that shows potent effects against osteoporosis; it has been authorized for clinical application in Japan since 2011. Studies have shown that eldecalcitol significantly increases BMD and reduces the risk of new vertebral fractures more effectively than alfacalcidol, a conventional active vitamin $\mathrm{D}_{3} .{ }^{31,32)}$ Because 
Table 2. Changes in parameters over 6 months of treatment by per-protocol analysis

\begin{tabular}{|c|c|c|c|c|}
\hline & \multicolumn{2}{|c|}{ Native D $(n=13)$} & \multicolumn{2}{|c|}{$\operatorname{ELD}(n=8)$} \\
\hline & Baseline & 6 months & Baseline & 6 months \\
\hline Age (years) & $78.0(69.5,83.0)$ & & $69.0(66.5,83.8)$ & \\
\hline Height (m) & $1.47(1.42,1.56)$ & & $1.48(1.45,1.55)$ & \\
\hline Weight (kg) & $48.0(45.0,53.0)$ & & $51.0(42.8,53.5)$ & \\
\hline $\operatorname{BMI}\left(\mathrm{kg} / \mathrm{m}^{2}\right)$ & $21.4(20.9,24.2)$ & & $21.7(20.2,24.5)$ & \\
\hline $\mathrm{TP}(\mathrm{g} / \mathrm{dL})$ & $6.8(6.6,7.8)$ & $6.8(6.6,7.4)$ & $7.0(6.7,7.6)$ & $7.1(6.9,7.6)$ \\
\hline $\operatorname{Alb}(\mathrm{g} / \mathrm{dL})$ & $4.2(4.1,4.5)$ & $4.2(4.1,4.5)$ & $4.4(4.3,4.7)$ & $4.4(4.3,4.6)$ \\
\hline BUN (mg/dL) & $17.5(14.9,19.8)$ & $15.7(14.4,20.7)$ & $16.8(13.8,24.3)$ & $16.4(14.2,22.7)$ \\
\hline Cre (mg/dL) & $0.67(0.55,0.77)$ & $0.64(0.56,0.76)$ & $0.61(0.54,0.73)$ & $0.66(0.55,0.76)$ \\
\hline eGFR $\left(\mathrm{ml} / \mathrm{min} / 1.73 \mathrm{~m}^{2}\right)$ & $61.9(55.0,83.9)$ & $68.2(55.2,79.0)$ & $74.5(58.7,81.7)$ & $67.5(56.1,82.5)$ \\
\hline 25(OH)D (ng/ml) & $30.0(25.0,37.0)$ & $36.0(32.0,49.5)^{\# *}$ & $26.5(22.0,45.0)$ & $27.0(19.5,38.0)$ \\
\hline $\mathrm{Ca}(\mathrm{mg} / \mathrm{dL})$ & $9.2(9.1,9.7)$ & $9.5(9.4,9.7)$ & $9.3(9.2,9.8)$ & $9.4(9.3,9.8)$ \\
\hline $\mathrm{P}(\mathrm{mg} / \mathrm{dL})$ & $3.2(3.1,3.6)$ & $3.3(3.0,3.5)^{\#}$ & $3.6(3.2,4.1)$ & $3.7(3.4,4.1)$ \\
\hline TRACP-5b (mU/dL) & $569.0(488.8,653.0)^{\#}$ & $216.0(136.0,280.0)^{* *}$ & $485.0(354.3,504.5)$ & $327.0(191.0,402.5)^{*}$ \\
\hline \multicolumn{5}{|l|}{ BMD } \\
\hline Lumbar spine $\left(\mathrm{g} / \mathrm{cm}^{2}\right)$ & $0.689(0.650,0.846)$ & $0.727(0.693,0.878)^{* *}$ & $0.676(0.619,0.777)$ & $0.706(0.657,0.792)$ \\
\hline YAM of lumbar spine (\%) & $68.0(64.0,83.5)$ & $72.0(68.5,86.5)^{* *}$ & $66.5(61.0,76.8)$ & $69.5(65.0,78.3)$ \\
\hline Proximal femur $\left(\mathrm{g} / \mathrm{cm}^{2}\right)$ & $0.568(0.509,0.643)$ & $0.577(0.533,0.649)$ & $0.528(0.488,0.557)$ & $0.536(0.492,0.557)$ \\
\hline YAM of femur $(\%)$ & $72.0(65.0,81.5)$ & $73.0(67.5,82.0)$ & $67.0(62.3,70.5)$ & $68.0(62.8,70.5)$ \\
\hline
\end{tabular}

All data are presented as median (interquartile range).

The Mann-Whitney U test was used for comparisons of baseline data or data after 6 months of treatment between the two groups and the Wilcoxon-signed rank test was used to make within-group comparisons.

$* \mathrm{P}<0.05$ versus baseline in the same group; $* * \mathrm{P}<0.01$ versus baseline in the same group.

${ }^{\#} \mathrm{P}<0.05$ versus the ELD group.

Table 3. Changes in muscle strength and postural balance over 6 months of treatment by per-protocol analysis

\begin{tabular}{lcccc}
\hline & \multicolumn{2}{c}{ Native D $(\mathrm{n}=13)$} & \multicolumn{2}{c}{ ELD $(\mathrm{n}=8)$} \\
\cline { 2 - 5 } & Baseline & 6 months & Baseline & 6 months \\
\hline Grip strength $(\mathrm{kg})$ & $21.3(18.6,22.9)$ & $20.8(16.4,23.1)$ & $23.7(17.4,25.6)$ & $21.7(12.2,25.2)$ \\
Back extensor strength (N) & $140(120.0,152.0)$ & $160.0(143.0,181.5)^{* *}$ & $145.5(98.8,170.5)$ & $130.0(85.5,181.0)$ \\
Hip flexor strength (N) & $155.2(144.0,186.5)$ & $155.5(148.7,205.2)$ & $163.5(106.4,175.0)$ & $127.9(102.1,175.7)$ \\
Knee extensor strength (N) & $164.8(155.0,199.0)$ & $173.3(165.5,221.5)^{*}$ & $159.7(149.2,167.7)$ & $160.9(136.0,188.5)$ \\
One-leg standing test (s) & $28.5(6.5,85.0)$ & $30.5(8.5,74.5)$ & $25.3(8.1,48.2)$ & $36.6(3.3,75.9)$ \\
10-m walk test (s) & $6.3(5.6,9.6)$ & $6.5(5.5,9.3)$ & $8.6(6.2,9.5)$ & $7.0(6.2,9.0)$ \\
FRT (cm) & $24.0(15.5,31.0)$ & $23.0(16.5,26.5)$ & $21.5(17.0,30.0)$ & $21.5(17.3,28.5)$ \\
TUG (s) & $6.7(5.4,8.3)$ & $6.8(5.8,7.8)$ & $8.2(6.6,9.7)$ & $7.8(6.5,10.0)$ \\
LNG (mm) & $2934(334)$ & $1972(225)^{*}$ & $3081(223)$ & $2248(332)^{*}$ \\
\hline
\end{tabular}

Data are shown as median (interquartile range), except for ${ }^{\mathrm{a}}$ values presented as mean (standard deviation).

Except for LNG, the Mann-Whitney U test was used for comparisons of baseline data or data after 6 months of treatment between the two groups and the Wilcoxon signed-rank test was used for within-group comparisons.

Student's $t$-test was used for comparisons of baseline data or data after 6 months of treatment between the two groups and the paired $t$-test was used to make within-group comparisons for LNG.

$* \mathrm{P}<0.05$ versus baseline in the same group, $* * \mathrm{P}<0.01$ versus baseline in the same group. 
Table 4. Percent changes in serum markers and muscle strength after 6 months of treatment by per-protocol analysis

\begin{tabular}{lccc}
\hline & Native D $(\mathrm{n}=13)$ & ELD $(\mathrm{n}=8)$ & P value \\
\hline 25(OH)D & $36.0(6.7,60.0)$ & $0.0(-17.1,0.6)$ & 0.010 \\
TRACP-5b & $-60.8(-67.0,-49.4)$ & $-20.1(-36.3,0.0)$ & 0.034 \\
Grip strength & $-1.5(-5.6,1.4)$ & $-0.1(-20.4,0.8)$ & 0.800 \\
Back extensor strength & $16.7(12.1,18.6)$ & $4.3(-2.9,17.9)$ & 0.185 \\
Hip flexor strength & $2.6(-0.2,8.9)$ & $0.0(-16.4,3.7)$ & 0.261 \\
Knee extensor strength & $7.9(6.8,9.2)$ & $0.0(-2.8,4.3)$ & 0.076 \\
\hline
\end{tabular}

Data are given as median (interquartile range).

$\mathrm{P}$ values were analyzed by the Mann-Whitney $\mathrm{U}$ test between the two groups.

of its potent effectiveness against osteoporosis, eldecalcitol is now the most commonly prescribed active vitamin $\mathrm{D}_{3}$ analog among the active vitamin $\mathrm{D}_{3}$ agents available in Japan. However, to the best of our knowledge, only two clinical studies into the effects of eldecalcitol on muscle and balance have been reported. ${ }^{9}{ }^{933}$ These two studies showed possible positive effects of eldecalcitol on strength and balance. ${ }^{9,33)}$

The results of the current study indicated that both native vitamin D and eldecalcitol are effective for improving dynamic sitting balance in postmenopausal women with osteoporosis who are undergoing denosumab treatment. We speculated that the improvement of dynamic sitting balance with eldecalcitol treatment was caused by an increase in back extensor strength. However, significant increases in back extensor and knee extensor strengths after treatment were seen only in the native D group, not in the ELD group. Our previous study demonstrated that eldecalcitol improved back muscle strength, iliopsoas muscle strength, and dynamic sitting balance in 18 subjects who completed 6 months of treatment. ${ }^{9)}$ This difference in the results for muscular strengths could have resulted from the different number of subjects in each group ( $n=13$ in the native $D$ group, $n=8$ in the ELD group). Another possible reason why the ELD group did not show a significant difference in knee or back extensor strength may have been the small number of subjects at follow-up.

This study is the first prospective, randomized, controlled study to examine the effects of native vitamin D and eldecalcitol on dynamic balance in patients with postmenopausal osteoporosis. However, the limitations of the current study should be considered. First, because of the complicated study protocol, this study enrolled a relatively small number of patients. Because the follow-up period was only 6 months, these limitations might have affected the study results. In this regard, this study must be considered to be preliminary in nature. Further studies with an increased number of sub- jects and a longer follow-up period are required to confirm our findings. Second, this study did not include a control group not administered any osteoporosis medication because this would have been ethically problematic. However, our previous work indicated that the LNG measured during the dynamic sitting balance test improved in an eldecalcitoltreated group, whereas that in a bisphosphonate-only group showed no improvement. ${ }^{9)}$ This result suggests the efficacy of vitamin $\mathrm{D}$ for improving dynamic sitting balance.

\section{CONCLUSIONS}

In conclusion, this preliminary, randomized, prospective study found that both native vitamin D + denosumab and eldecalcitol + denosumab were effective for improving dynamic sitting balance in postmenopausal women with osteoporosis. No significant differences between native vitamin $\mathrm{D}$ and eldecalcitol were seen in terms of their effects on muscle strength and balance.

\section{ACKNOWLEDGMENTS}

We wish to thank Drs. Nobuhiko Shimoma and Norikazu Konno for their cooperation in conducting the study.

\section{CONFLICTS OF INTEREST}

Naohisa Miyakoshi has received payments for lectures from Daiichi Sankyo and Chugai Pharmaceutical Co., Ltd. The other authors declare that they have no conflicts of interest.

\section{REFERENCES}

1. Tinetti ME, Kumar C: The patient who falls: "It's always a trade-off”. JAMA 2010;303:258-266. DOI:10.1001/ jama.2009.2024, PMID:20085954 
2. Kapteyn TS, Bles W, Njiokiktjien CJ, Kodde L, Massen $\mathrm{CH}$, Mol JM: Standardization in platform stabilometry being a part of posturography. Agressologie 1983;24:321-326. PMID:6638321

3. Podsiadlo D, Richardson S: The timed "Up \& Go": a test of basic functional mobility for frail elderly persons. J Am Geriatr Soc 1991;39:142-148. DOI:10.1111/j.1532-5415.1991.tb01616.x, PMID:1991946

4. Duncan PW, Weiner DK, Chandler J, Studenski S: Functional reach: a new clinical measure of balance. J Gerontol 1990;45:M192-M197. DOI:10.1093/ geronj/45.6.M192, PMID:2229941

5. Gabell A, Simons MA, Nayak US: Falls in the healthy elderly: predisposing causes. Ergonomics 1985;28:965975. DOI:10.1080/00140138508963219, PMID:4043031

6. Bhatt T, Espy D, Yang F, Pai YC: Dynamic gait stability, clinical correlates, and prognosis of falls among community-dwelling older adults. Arch Phys Med Rehabil 2011;92:799-805. DOI:10.1016/j.apmr.2010.12.032, PMID:21530728

7. Masutani N, Iwami T, Matsunaga T, Saito K, Tsuchie H, Takahashi Y, Shimada Y: Trunk balance evaluation in adolescent athletes and gender difference using the dynamic sitting balance device. Int J Phys Med Rehabil 2018;06:1. DOI:10.4172/2329-9096.1000455

8. Saito K, Matsunaga T, Iwami T, Shimada Y: Evaluation of trunk stability in the sitting position using a new device. Biomed Res 2014;35:127-131. DOI:10.2220/ biomedres.35.127, PMID:24759180

9. Saito K, Miyakoshi N, Matsunaga T, Hongo M, Kasukawa Y, Shimada Y: Eldecalcitol improves muscle strength and dynamic balance in postmenopausal women with osteoporosis: an open-label randomized controlled study. J Bone Miner Metab 2016;34:547-554. DOI:10.1007/s00774-015-0695-x, PMID:26209166

10. Bischoff-Ferrari HA, Dawson-Hughes B, Staehelin HB, Orav JE, Stuck AE, Theiler R, Wong JB, Egli A, Kiel DP, Henschkowski J: Fall prevention with supplemental and active forms of vitamin D: a meta-analysis of randomised controlled trials. BMJ 2009;339(oct01 1):b3692. DOI:10.1136/bmj.b3692, PMID:19797342

11. Murad MH, Elamin KB, Abu Elnour NO, Elamin MB, Alkatib AA, Fatourechi MM, Almandoz JP, Mullan RJ, Lane MA, Liu H, Erwin PJ, Hensrud DD, Montori VM: Clinical review: the effect of vitamin D on falls: a systematic review and meta-analysis. J Clin Endocrinol Metab 2011;96:2997-3006. DOI:10.1210/jc.2011-1193, PMID:21795448
12. Pfeifer M, Begerow B, Minne HW, Suppan K, Fahrleitner-Pammer A, Dobnig H: Effects of a long-term vitamin $\mathrm{D}$ and calcium supplementation on falls and parameters of muscle function in community-dwelling older individuals. Osteoporos Int 2009;20:315-322. DOI:10.1007/s00198-008-0662-7, PMID:18629569

13. Wu H, Pang Q: The effect of vitamin D and calcium supplementation on falls in older adults. Orthopade 2017;46:729-736. DOI:10.1007/s00132-017-3446-y, PMID:28718008

14. Bone HG, Wagman RB, Brandi ML, Brown JP, Chapurlat R, Cummings SR, Czerwiński E, FahrleitnerPammer A, Kendler DL, Lippuner K, Reginster JY, Roux C, Malouf J, Bradley MN, Daizadeh NS, Wang A, Dakin P, Pannacciulli N, Dempster DW, Papapoulos S: 10 years of denosumab treatment in postmenopausal women with osteoporosis: results from the phase 3 randomised FREEDOM trial and open-label extension. Lancet Diabetes Endocrinol 2017;5:513-523. DOI:10.1016/S2213-8587(17)30138-9, PMID:28546097

15. Brown JP, Prince RL, Deal C, Recker RR, Kiel DP, de Gregorio LH, Hadji P, Hofbauer LC, Álvaro-Gracia JM, Wang H, Austin M, Wagman RB, Newmark R, Libanati C, San Martin J, Bone HG: Comparison of the effect of denosumab and alendronate on BMD and biochemical markers of bone turnover in postmenopausal women with low bone mass: a randomized, blinded, phase 3 trial. J Bone Miner Res 2009;24:153-161. DOI:10.1359/jbmr.0809010, PMID:18767928

16. Cummings SR, Martin JS, McClung MR, Siris ES, Eastell R, Reid IR, Delmas P, Zoog HB, Austin M, Wang A, Kutilek S, Adami S, Zanchetta J, Libanati C, Siddhanti S, Christiansen C, FREEDOM Trial: Denosumab for prevention of fractures in postmenopausal women with osteoporosis. N Engl J Med 2009;361:756765. DOI:10.1056/NEJMoa0809493, PMID:19671655

17. McClung MR, Lewiecki EM, Geller ML, Bolognese MA, Peacock M, Weinstein RL, Ding B, Rockabrand E, Wagman RB, Miller PD: Effect of denosumab on bone mineral density and biochemical markers of bone turnover: 8-year results of a phase 2 clinical trial. Osteoporos Int 2013;24:227-235. DOI:10.1007/s00198012-2052-4, PMID:22776860 
18. Soen S, Fukunaga M, Sugimoto T, Sone T, Fujiwara S, Endo N, Gorai I, Shiraki M, Hagino H, Hosoi T, Ohta H, Yoneda T, Tomomitsu T, Japanese Society for Bone and Mineral Research and Japan Osteoporosis Society Joint Review Committee for the Revision of the Diagnostic Criteria for Primary Osteoporosis: Diagnostic criteria for primary osteoporosis: year 2012 revision. J Bone Miner Metab 2013;31:247-257. DOI:10.1007/ s00774-013-0447-8, PMID:23553500

19. Bandirali M, Sconfienza LM, Aliprandi A, Di Leo G, Marchelli D, Ulivieri FM, Sardanelli F: In vivo differences among scan modes in bone mineral density measurement at dual-energy X-ray absorptiometry. Radiol Med (Torino) 2014;119:257-260. DOI:10.1007/ s11547-013-0342-3, PMID:24297585

20. Limburg PJ, Sinaki M, Rogers JW, Caskey P, Pierskalla BK: A useful technique for measurement of back strength in osteoporotic and elderly patients. Mayo Clin Proc 1991;66:39-44. DOI:10.1016/S00256196(12)61173-2, PMID:1824867

21. Bohannon RW: Comfortable and maximum walking speed of adults aged 20-79 years: reference values and determinants. Age Ageing 1997;26:15-19. DOI:10.1093/ ageing/26.1.15, PMID:9143432

22. Duncan PW, Weiner DK, Chandler J, Studenski S: Functional reach: a new clinical measure of balance. J Gerontol 1990;45:M192-M197. DOI:10.1093/ geronj/45.6.M192, PMID:2229941

23. Ng SS, Hui-Chan CW: The timed up \& go test: its reliability and association with lower-limb impairments and locomotor capacities in people with chronic stroke. Arch Phys Med Rehabil 2005;86:1641-1647. DOI:10.1016/j.apmr.2005.01.011, PMID:16084820

24. Masutani N, Iwami T, Matsunaga T, Saito K, Tsuchie H, Takahashi Y, Shimada Y: A study of the reliability of a new dynamic trunk balance measuring device. Int J Phys Med Rehabil 2017;05:6. DOI:10.4172/2329-9096.1000443

25. Holick MF: The vitamin D deficiency pandemic: approaches for diagnosis, treatment and prevention. Rev Endocr Metab Disord 2017;18:153-165. DOI:10.1007/ s11154-017-9424-1, PMID:28516265

26. Garland CF, Kim JJ, Mohr SB, Gorham ED, Grant WB, Giovannucci EL, Baggerly L, Hofflich H, Ramsdell JW, Zeng K, Heaney RP: Meta-analysis of all-cause mortality according to serum 25-hydroxyvitamin D. Am J Public Health 2014;104:e43-e50. DOI:10.2105/ AJPH.2014.302034, PMID:24922127
27. Ceglia L, Niramitmahapanya S, da Silva Morais M, Rivas DA, Harris SS, Bischoff-Ferrari H, Fielding RA, Dawson-Hughes B, Fielding RA, Dawson-Hughes B: A randomized study on the effect of vitamin $\mathrm{D}_{3}$ supplementation on skeletal muscle morphology and vitamin D receptor concentration in older women. J Clin Endocrinol Metab 2013;98:E1927-E1935. DOI:10.1210/ jc.2013-2820, PMID:24108316

28. Bischoff-Ferrari HA, Borchers M, Gudat F, Dürmüller U, Stähelin HB, Dick W: Vitamin D receptor expression in human muscle tissue decreases with age. J Bone Miner Res 2004;19:265-269. DOI:10.1359/ jbmr.2004.19.2.265, PMID:14969396

29. Wolfson L, Judge J, Whipple R, King M: Strength is a major factor in balance, gait, and the occurrence of falls. J Gerontol ABiol SciMed Sci 1995;50:64-67.DOI:10.1093/ gerona/50a.special_issue.64, PMID:7493221

30. Nakamura T, Takano T, Fukunaga M, Shiraki M, Matsumoto T: Eldecalcitol is more effective for the prevention of osteoporotic fractures than alfacalcidol. J Bone Miner Metab 2013;31:417-422. DOI:10.1007/ s00774-012-0418-5, PMID:23575909

31. Hagino H, Takano T, Fukunaga M, Shiraki M, Nakamura T, Matsumoto T: Eldecalcitol reduces the risk of severe vertebral fractures and improves the healthrelated quality of life in patients with osteoporosis. J Bone Miner Metab 2013;31:183-189. DOI:10.1007/ s00774-012-0397-6, PMID:23129180

32. Matsumoto T, Ito M, Hayashi $Y$, Hirota T, Tanigawara Y, Sone T, Fukunaga M, Shiraki M, Nakamura T: A new active vitamin D3 analog, eldecalcitol, prevents the risk of osteoporotic fractures - a randomized, active comparator, double-blind study. Bone 2011;49:605-612. DOI:10.1016/j.bone.2011.07.011, PMID:21784190

33. Iwamoto J, Sato Y: Eldecalcitol improves chairrising time in postmenopausal osteoporotic women treated with bisphosphonates. Ther Clin Risk Manag 2014;10:51-59. DOI:10.2147/TCRM.S54772, PMID:24476669 